\title{
Design and Characterization of Third Generation Current Conveyor
}

\author{
Payal shah ${ }^{1}$, Amisha Naik ${ }^{2}$ \\ '(Department of EC, LDRP University, Gandhinagar India) \\ ${ }^{2}$ (Department of EC, Nirma University, Ahmedabad India)
}

\begin{abstract}
This paper presents a low power low voltage positive third generation current conveyor using four simple first generation current conveyors. It is designed and simulated in a standard 0.18um TSMC 1P, 6M CMOS process. This current conveyor design with the help of design architect and IC station (mentor graphics). Its DC, AC and transient analysis is carried out with ELDO tool. Its pre layout and post layout results are also given.
\end{abstract}

Keywords: Current mode circuit, third generation current conveyor

\section{Introduction}

For LV, LP applications, current conveyors becoming very popular analogue building block now a days. Current conveyors are operated on the current mode approach [7,8], which considers the information flowing on time varying currents. Current conveyors overcome many disadvantages of voltage mode op-amp.

1. When signals are widely distributed as voltages, the parasitic capacitances are charged and discharged with the full voltage swing, which limits the speed and increase the power consumption of voltage mode circuits [6].

2. In voltage mode designs the bandwidth is limited at high closed loop gains due to the constant gainbandwidth product. Furthermore, the limited slew-rate of the operational amplifier affects the large signal, high frequency operation [6].

3. The MOS transistors are more suitable for processing currents rather than voltages [6].

4. MOS current-mirrors are more accurate and less sensitive to process variation than bipolar current-mirrors [5].

A current conveyor has current mode as well as voltage mode applications. Current conveyors are classified mainly in to three types. CC I(first generation current conveyor), CCII(second generation current conveyor), CCIII(third generation current conveyor). It shows below in the matrix form:

$$
\left(\begin{array}{c}
I y \\
V x \\
I z
\end{array}\right)=\left(\begin{array}{lll}
0 & a & 0 \\
1 & 0 & 0 \\
0 & b & 0
\end{array}\right)\left(\begin{array}{c}
V y \\
I x \\
V z
\end{array}\right)
$$

If $\mathrm{a}=1$, Iy $=\mathrm{Ix}$, which shows first generation current conveyor. If $\mathrm{a}=0$, Iy $=0$, which shows second generation current conveyor. If $\mathrm{a}=-1, \mathrm{Iy}=-\mathrm{Ix}$, which shows third generation current conveyor. $\mathrm{b}= \pm 1$, which shows $\mathrm{Iz}= \pm \mathrm{Ix}$, which shows either positive or negative current conveyor.

\section{Third generation current conveyor}

Third generation current conveyor (CCIII) was proposed by fabre in 1995.Its first CMOS implementation is done by A. Piovaccari. It is shown below in matrix form:

$$
\left(\begin{array}{c}
I y \\
V x \\
I z
\end{array}\right)=\left(\begin{array}{ccc}
0 & -1 & 0 \\
1 & 0 & 0 \\
0 & 1 & 0
\end{array}\right)\left(\begin{array}{c}
V y \\
I x \\
V z
\end{array}\right)
$$


CCIII works same as CCI except that the currents in ports X and Y flow in opposite directions. Here, Iz current follows current flowing in to the $\mathrm{X}$ terminal. It is a push-pull conveyor built from four simple first generation current conveyors [5]. Thus, the $\mathrm{X}$ and $\mathrm{Y}$ terminal impedances are maintained comparable low [5]. The third generation current conveyors (CCIIIs) can be considered as a current controlled current source with a unity gain [10]. Its schematic view is shown below.

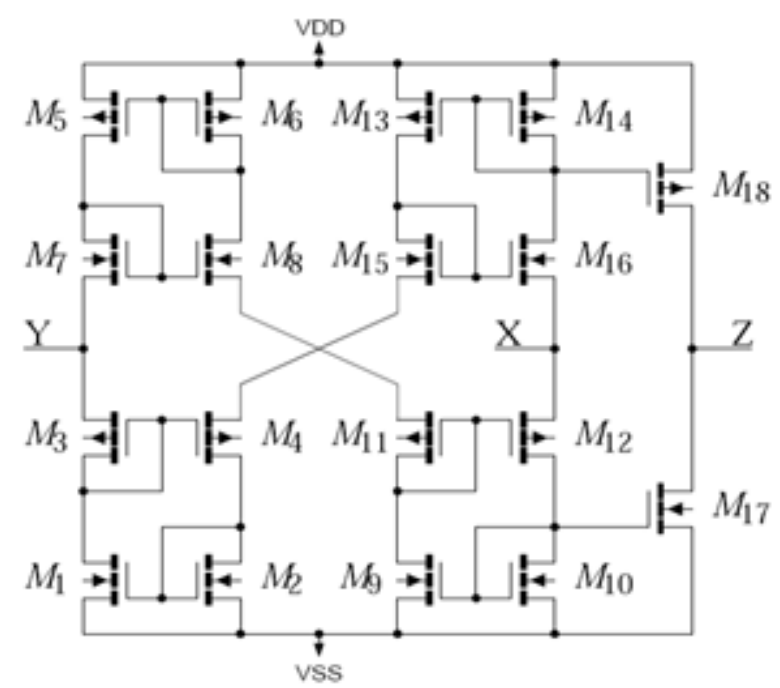

Fig. 1.Schematic of CCIII

This type of the current conveyor is useful to take out the current flowing through a floating branch of a circuit and can be utilized in realization of various multifunction filters, inductance simulation and all pass sections [10]. The dimensions of the MOS transistors are given below in table1.

Table 1.Aspect ratio of transistors of Fig.1

\begin{tabular}{|c|c|c|}
\hline Transistor & $\mathrm{W}($ in $\mu \mathrm{m})$ & $\mathrm{L}($ in $\mu \mathrm{m})$ \\
\hline M3,M8 & 6.84 & 0.35 \\
\hline M2,M6 & 4.24 & 0.35 \\
\hline M4,M5 & 1.24 & 0.35 \\
\hline M7,M9 & 4.04 & 0.35 \\
\hline M11,M16 & 2.5 & 0.35 \\
\hline M10,M14 & 1.4 & 0.35 \\
\hline M12,M13 & 1.2 & 0.35 \\
\hline M15,M17,M19 & 1.44 & 0.35 \\
\hline M18 & 1.14 & 0.35 \\
\hline
\end{tabular}

\section{Simulation Results}

The performances of presented CCIII are verified by Mentor Graphics simulation program using TSMC 0.18 um CMOS technology. Here $\pm 1.8 \mathrm{~V}$ input supply is used for the operation of CCIII. For this circuit DC bias current value is set to $5 \mu \mathrm{A}$.

The main DC and AC characteristics of the CCIII, such as plots of Vx versus $\mathrm{Vy}$, plots of Iz+ and Iy versus Ix, frequency responses of $\mathrm{Vx} / \mathrm{Vy}$ and $\mathrm{Iz}+/ \mathrm{Ix}$ are obtained.

The DC transfer characteristic of Vx versus $\mathrm{Vy}$ is shown in fig.2. Here input voltage is applied to $\mathrm{Y}$ terminal, output is taken from the $\mathrm{X}$ terminal with infinite load resistance connected to $\mathrm{X}$ terminal [10]. Z terminal is being grounded .Here linearity range is obtained from $-1.14 \mathrm{~V}$ to $1.14 \mathrm{~V}$.

Fig. 3 shows DC transfer characteristics for Ix, Iy and Iz+terminal. To obtained DC current waveforms, terminal $\mathrm{X}$ and terminal $\mathrm{Z}$ is being short circuited. Here maximum and minimum limits of the current $\mathrm{Iz}^{+}$is obtained as: $\mathrm{Iz}+\max =0.93 \mathrm{~mA}, \mathrm{Iz}+\mathrm{min}=-0.39 \mathrm{~mA}$.

Fig.4 shows the AC characteristics of voltages $\mathrm{Vx}$ and $\mathrm{Vy}$. 
$\mathrm{f}_{-3 \mathrm{db}}$ frequency of $(\mathrm{Vx} / \mathrm{Vy})$ is $1.24 \mathrm{GHz}$. fig. 5 shows current waveforms. For $(\mathrm{Iz}+/ \mathrm{Ix}), \mathrm{f}_{-3 \mathrm{db}}$ frequency is 80.65Mhz.Fig.6 shows waveforms of trans impedance $\mathrm{Rx}, \mathrm{Rz}$ as $26.98 \mathrm{~K} \Omega$ and $25.68 \mathrm{~K} \Omega$ respectively. Fig.7 shows transient analysis of voltages $\mathrm{Vx}, \mathrm{Vy}$.

Fig.8 shows layout of third generation current conveyor. This layout is simulated using IC station of mentor graphics. Results of post layout are depicted in Table 2.

Table 2 summarized performance characteristics of CCIII.

\section{Conclusion}

CCIII is simulated and analyzed for pre layout and post layout design. It has good gain and high bandwidth. It uses low voltage and consumes low power. Here current gain will be improved by increasing trans impedance at $\mathrm{X}$ and $\mathrm{Z}$ terminals. Voltage gain will be improved by using modified topologies. By analyzing results, it is assured that current mode circuits give better performance in low voltage low power applications as compared with voltage mode circuits.

\section{Acknowledgment}

I would like to thank Dr. N.M.Devashrayee, coordinator of M. Tech EC- VLSI Design, Institute of Technology, Nirma University for providing encouragement, constant guidance and kind support throughout this time interval. I would like to thank my guide Dr. Amisha Naik from the bottom of my heart who taught me many fundamental theories of current mode circuits. I would like to thank Mr. Prasanna shukla,lab in charge of M. Tech EC VLSI Design for his support.

\section{References}

[1]. FABRE, A.: 'Third-generation current conveyor: A new helpful active element', Electron. Lett.. 1995, 31, (9, pp. 338-339

[2]. BRUUN, E.: 'Class AB CMOS first-generation current conveyor', Electron. Lett.. 1995, 31, (6), pp. 422423

[3]. A. Piovaccari, “CMOS integrated third-generation conveyor,” Electronics Letters, Vol. 31, No. 15, pp. 1228-1229, 1995

[4]. Giuseppe Ferri and Nicola C. Guerrini."Low Voltage Low Power CMOS Current Conveyors"by Pg no.126-128

[5]. Kimmo Koli,,"CMOS Current Amplifiers:Speed versus Nonlinearity",Ph.D,Dissertation,Helsinki University of Technology,Finalnd,Oct-2000.

[6]. Amisha Naik.,"Novel Topologies of second generation current conveyors for low power low voltage applications",Ph.D, Dissertation, Nirma University, Ahmedabad, May-2011.

[7]. C.Toumazou,A.Payne,D.Haigh.Analogue IC design:The current mode approach.Peter Peregrinus 1990.

[8]. G.Palumbo, S.Palmisano, S.Pennisi .CMOS current amplifiers. Boston: Kluwer Academic Publishers, 1999.

[9]. Nadhmia Bouaziz El Feki,Dorra Sellami Masmoudi,"High Performance Dual-Output Second and Third Generation Current Conveyors and Current-Mode Multifunction Filter Application", $6^{\text {th }}$ International Multi-Conference on Systems, Signals and Devices, 2009.

[10]. S.Minaei,M.Yildiz,H.Kuntman, S.turkoz,'High performance CMOS realization of the third generation current conveyor(CCIII),IEEE,2002.

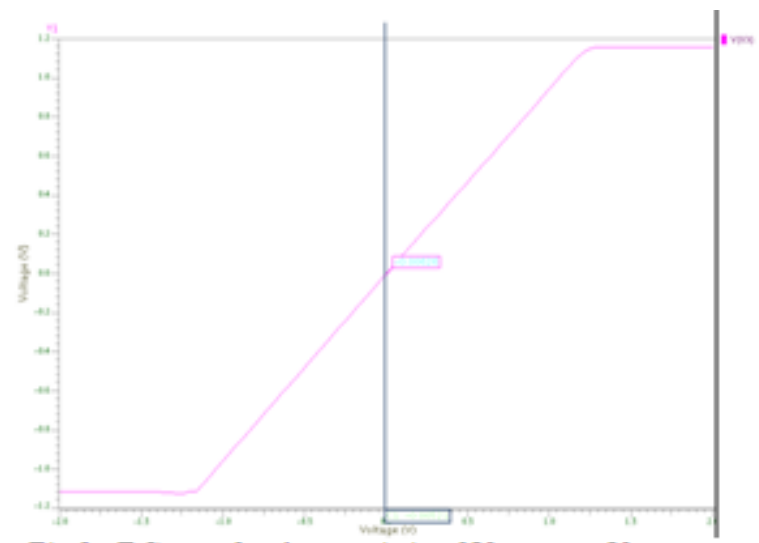

Fig.2: DC transfer characteristic of $\mathrm{Vx}$ versus $\mathrm{Vy}$ 


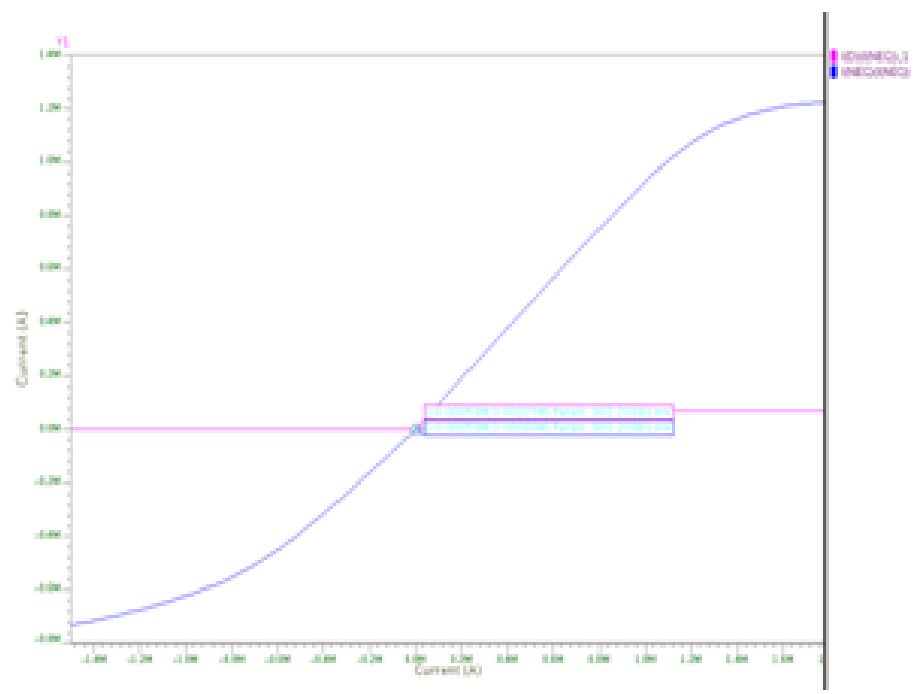

Fig.3: DC transfer characteristic of Iy, Ix and Iz+

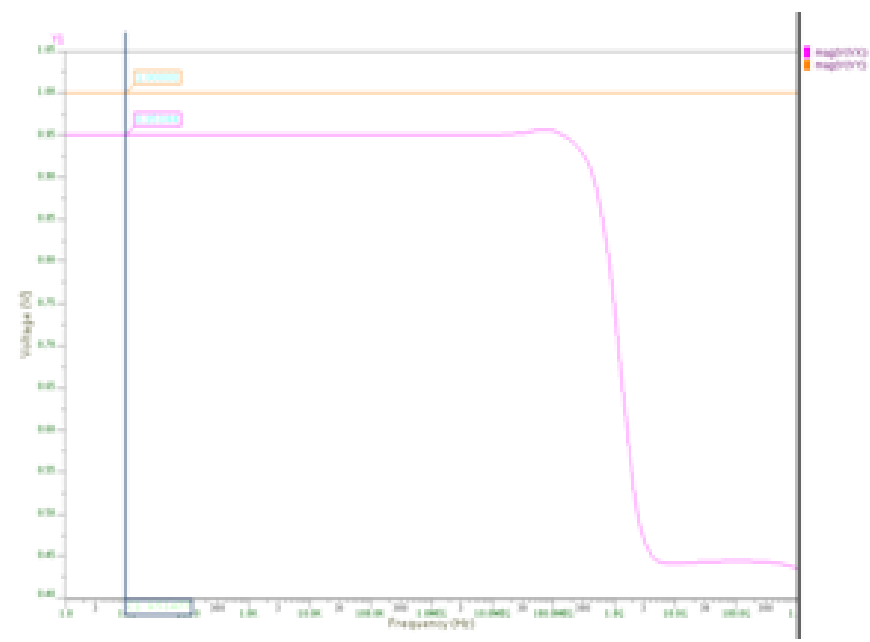

Fig.4: AC response of voltages $\mathrm{Vx}, \mathrm{Vy}$

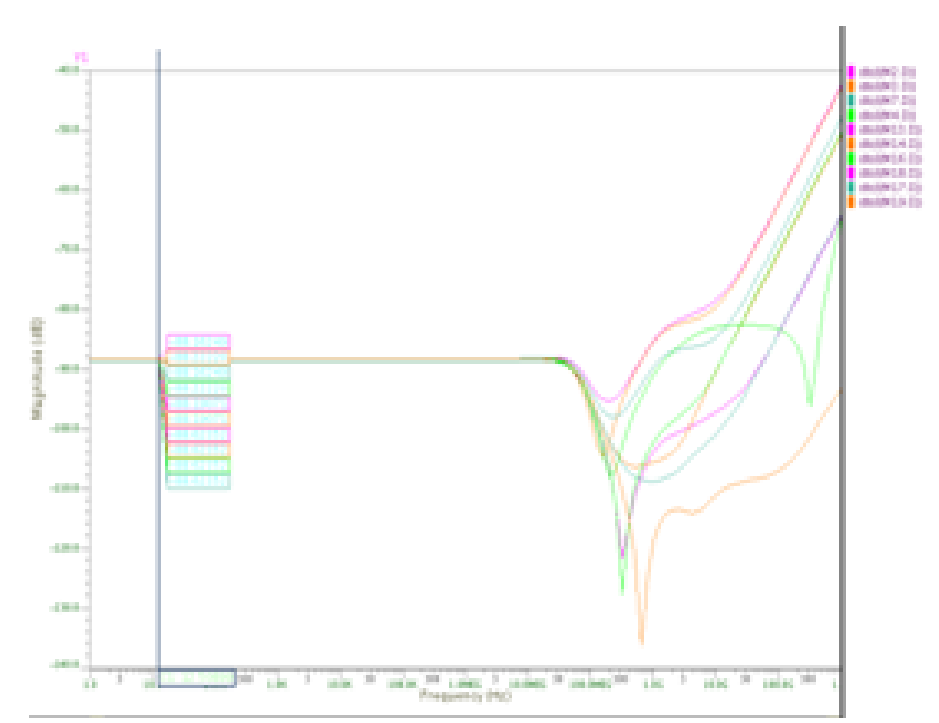

Fig.5: AC response of currents $\mathrm{Ix}, \mathrm{Iy}, \mathrm{Iz}+$ 


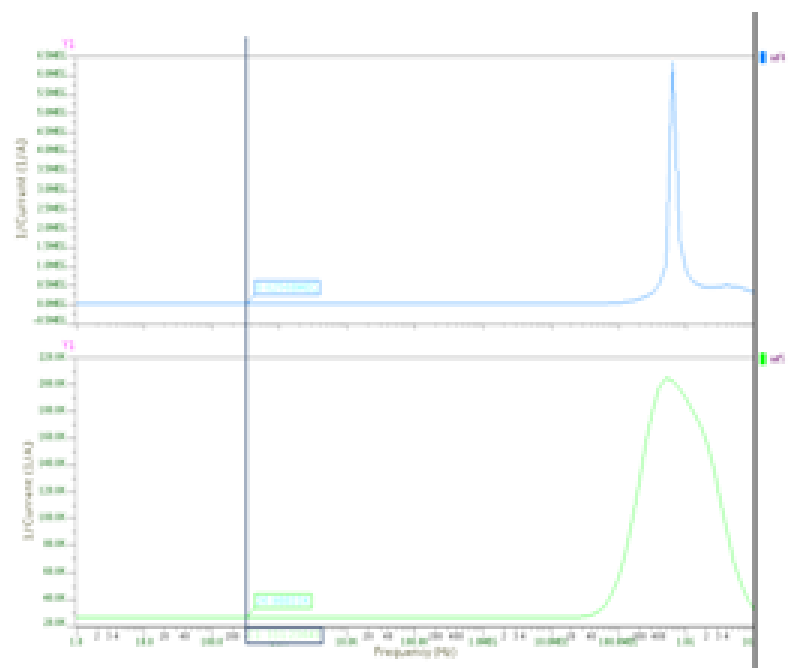

Fig.6: $A C$ response of trans, impedance $R x, R z$.

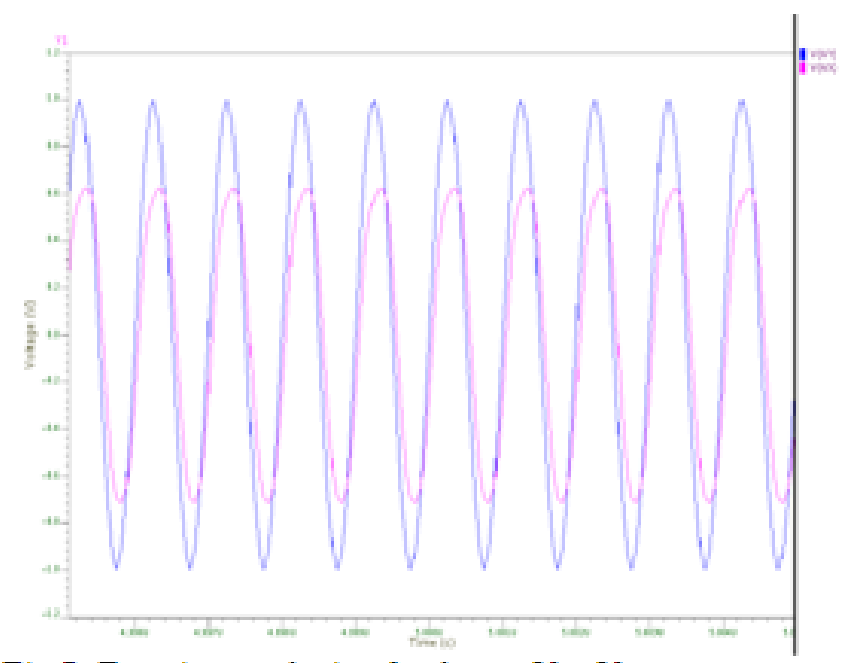

Fig.7: Transient analysis of voltages $\mathrm{Vx}, \mathrm{Vy}$

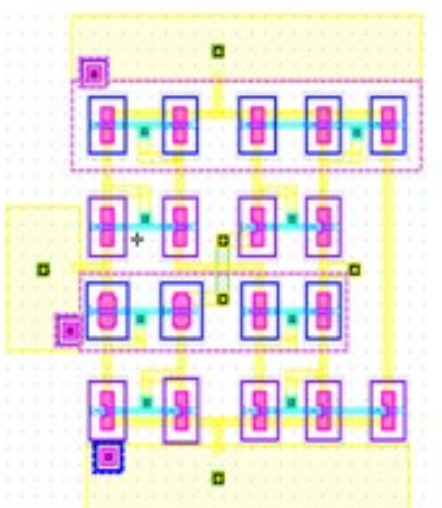

Fig.8: Layout of third generation current conveyor 
Table 2: Performance Characteristic of Fig.1

\begin{tabular}{|c|c|c|}
\hline Parameter & Pre layout results & Post layout results \\
\hline CMOS technology & $0.18 \mu \mathrm{m}$ & $0.18 \mu \mathrm{m}$ \\
\hline Voltage supply & $\pm 1.8 \mathrm{~V}$ & $5 \mu \mathrm{A}$ \\
\hline DC bias current & $5 \mu \mathrm{A}$ & $-1.14 \mathrm{~V}$ to $1.14 \mathrm{~V}$. \\
\hline $\begin{array}{c}\text { Dynamic swing } \\
\text { Vx-Vy }\end{array}$ & $-1.14 \mathrm{~V}$ to $1.14 \mathrm{~V}$ & $0.93 \mathrm{~mA}$ to $-0.39 \mathrm{~mA}$ \\
\hline Dynamic swing Iz+-Ix & & $0.93 \mathrm{~mA}$ to $-0.39 \mathrm{~mA}$ \\
\hline Vx/Vy accuracy \\
(voltage gain) & 0.95 & 1.05 \\
\hline Iz+/Ix accuracy & 1.05 & 0.95 \\
\hline Ix/Iy accuracy & 0.95 & $1.22 \mathrm{GHz}$ \\
\hline Vx/Vy f-3db & $1.24 \mathrm{GHz}$ & $77.81 \mathrm{MHz}$ \\
\hline Iz+/Ix f-3db & $80.65 \mathrm{MHz}$ & $26.988 \mathrm{~K} \Omega$ \\
\hline Trans impedance(Rx) & $26.988 \mathrm{~K} \Omega$ & $25.68 \mathrm{~K} \Omega$ \\
\hline Trans impedance(Rz) & $25.68 \mathrm{~K} \Omega$ & $256.67 \mu \mathrm{watt}$ \\
\hline Power dissipation & $256.64 \mu \mathrm{watt}$ & \\
\hline
\end{tabular}

